Stroke

Volume 27, Issue 10, October 1996; Pages 1798-1803

https://doi.org/10.1161/01.STR.27.10.1798

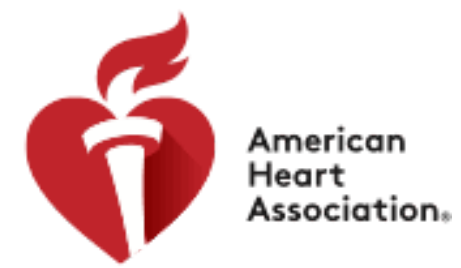

\title{
ARTICLE
}

\section{Recovery of Cognitive Function After Stroke}

David W. Desmond, Joan T. Moroney, Mary Sano, and Yaakov Stern

Background and Purpose Previous studies have

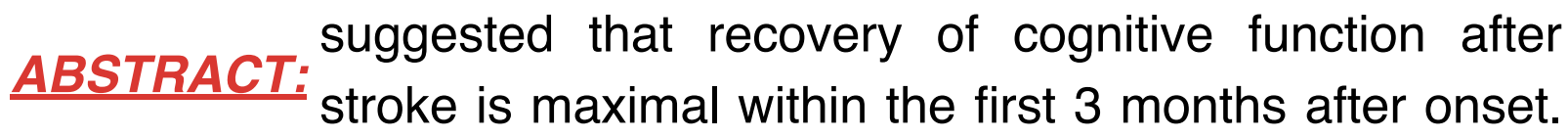
We performed the present study to investigate the long-term course and clinical correlates of improvement in generalized cognitive function after ischemic stroke. Methods We administered a battery of neuropsychological tests to 151 patients (age, 70.4 \pm 7.7 years; education, $10.4 \pm 4.6$ years) at 3 months and then annually after stroke. We transformed their test results into $z$ scores based on the performance of a stroke-free normative group, averaged those scores to create a summary score, and defined improvement in annual examinations as an increase in that summary score greater than two standard deviations above the mean first annual change of the normative group. We then used logistic regression to determine whether stroke location, syndrome, or recurrence; vascular risk factors; dementia status; depression; or demographic variables were associated with improvement.Results We found that 19 of the 151 patients exhibited improvement, which was evident only at the first annual examination in most cases. Logistic regression determined that improvement was significantly related to left hemisphere 
infarction relative to brain stem/cerebellar infarction (odds ratio [OR], 5.57), while the presence of a major hemispheral stroke syndrome showed a trend toward significance (OR, 3.32). Diabetes mellitus was significantly associated with a failure to exhibit improvement (OR, 0.12). Based on the logistic model, the probability of long-term improvement would be $54.0 \%$ for a patient with a left hemisphere infarct and a major hemispheral syndrome but only $11.9 \%$ if diabetes was also present.Conclusions Long-term improvement in generalized cognitive function may be evident after stroke in association with left hemisphere infarction and severe hemispheral syndromes, while it may be compromised by diabetes, possibly because of an increased burden of cerebrovascular disease.

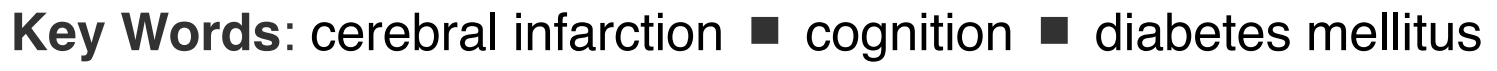
stroke outcome

Copyright $\odot 1996$ by American Heart Association

t is understood that stroke frequently produces cognitive dysfunction. Among numerous studies focusing on that topic, we found that $35.2 \%$ of a sample of 227 stroke patients examined 3 months after stroke failed 4 or more of the 17 neuropsychological measures that they were administered while only $3.8 \%$ of a sample of 240 stroke-free control subjects met that criterion, with strokerelated cognitive impairment significantly associated with functional dependence after hospital discharge. ${ }^{1}$ Regarding severe cognitive impairment, we diagnosed stroke-related dementia in $16.3 \%$ of the 227 stroke patients at that same examination, ${ }^{2}$ and other groups have reported an elevated risk of dementia associated with cerebrovascular disease in medical inpatient ${ }^{3}$ and community- 
based $^{4} 56$ samples. Although long-term prospective studies of cognitive function after stroke have been performed to investigate cognitive decline ${ }^{7}$ and incident dementia, ${ }^{8} 91011$ studies of recovery have tended to focus on improvement in specific cognitive functions occurring within the first 3 months after stroke. ${ }^{12} 1314$

We performed the present study to determine whether long-term improvement in generalized cognitive function can occur after stroke and to identify clinical characteristics that might be associated with improvement. Regardless of whether long-term improvement in cognitive function would be evident or clinical predictors identifiable, however, the results of our investigation should permit more accurate determinations regarding the prognosis for cognitive recovery of patients after stroke.

\section{SUBJECTS AND METHODS}

\section{Subjects}

As part of a prospective study of stroke and dementia, ${ }^{2}$ we examined 151 patients (age, $70.4 \pm 7.7$ years; education, $10.4 \pm 4.6$ years) at 3 months and then annually after ischemic stroke. Those patients were selected from a larger sample of 251 consecutively admitted patients $\geq 60$ years of age who were examined 3 months after stroke. The remaining patients were excluded because they did not receive a complete neuropsychological evaluation at the 3-month and/or one subsequent annual examination $(n=76)$ or because they had received a diagnosis of possible Alzheimer's disease with stroke based on a premorbid history of functional impairment and baseline neuropsychological testing consistent with dementia $(n=24)$. Patients who had received a diagnosis of possible Alzheimer's disease with stroke were excluded because the course of gradually progressive 
cognitive decline that is typically evident in Alzheimer's disease could have compromised our ability to identify any long-term improvement in cognitive function that might occur after stroke.

To derive an estimate of the amount of variation in neuropsychological test performance that might be expected during the course of 1 year in elderly subjects free of stroke, we also examined 192 stroke-free nondemented control subjects (age, $71.0 \pm 6.2$ years; education, $13.0 \pm 4.1$ years) at baseline and then 1 year later. They were selected from a larger cohort of 249 subjects. The remaining subjects were excluded because they did not receive complete neuropsychological evaluations at the baseline and/or the first annual examination $(n=48)$ or because they had received a diagnosis of probable Alzheimer's disease based on a history of functional impairment and baseline neuropsychological testing consistent with dementia $(n=9)$. The majority of the control sample was randomly selected from Medicare records and a commercial list, while the remainder of the sample was composed of volunteers from the community and spouses of stroke patients.

This study was approved by the institutional review board of our medical center and all subjects provided informed consent.

\section{Test Instruments}

Cognitive testing was performed in either English or Spanish, depending on the language spoken in the subject's home. We administered a battery of neuropsychological tests developed for use in epidemiological studies of dementia ${ }^{15}$ to all subjects. Given that this battery was designed for use in the diagnosis of dementia rather than simply the assessment of demented patients, most of these tests were challenging and not subject to a ceiling effect in our sample. This battery included measures of verbal and nonverbal memory (the Selective Reminding Test and a multiple-choice 
recognition version of the Benton Visual Retention Test), orientation (the Mini-Mental State Examination orientation subtest), language (a 15-item version of the Boston Naming Test, letter and category fluency tests, and the repetition and complex ideation subtests of the Boston Diagnostic Aphasia Examination), visuospatial function (the Rosen Drawing Test and a multiple-choice matching version of the Benton Visual Retention Test), verbal and nonverbal abstract reasoning skills (the Similarities subtest of the WAIS-R and the Identities and Oddities subtest of the Mattis Dementia Rating Scale), and attention (cancellation tasks using shapes and letters as targets).

\section{Additional Procedures}

Neurologists specializing in stroke documented any history of stroke, transient ischemic attack, or exposure to risk factors for cerebrovascular disease based on a structured interview administered to all patients and/or review of medical records. Based on the review of clinical features and CT scans performed immediately after stroke, patients were classified by infarct location and stroke syndrome using a modification of the methods of the Stroke Data Bank. ${ }^{16}$ Infarct location was classified as left hemisphere, right hemisphere, or brain stem/cerebellar. Presenting stroke syndrome was classified as major hemispheral or other, reflecting the range and severity of neurological deficits. Classifications of stroke location and syndrome were made independently of the neuropsychological test results. Additional information regarding our methods is available in other publications. ${ }^{2}$ 17

\section{Statistical Analyses}


To determine whether any selection bias might have resulted from the exclusion of a large proportion of the stroke patients in the baseline cohort, $x^{2}$ analyses were performed to compare the patients who were excluded from this study with those patients who were included with regard to demographic variables (ie, age, education, race, and sex); vascular risk factors (ie, hypertension, diabetes mellitus, cardiac disease, hypercholesterolemia, consistent cigarette use, and consistent alcohol use); prior stroke; prior transient ischemic attack; stroke location (ie, left and right hemispheres versus brain stem or cerebellum); severity of presenting stroke syndrome (ie, major hemispheral syndrome versus other); aphasia (ie, mild or moderate severity of any subtype of aphasia versus the absence of aphasia, with severely aphasic subjects having been excluded from enrollment in the larger study); neglect; dementia status, diagnosed using operationalized methods described previously ${ }^{2}$; depression, diagnosed using the Hamilton Depression Rating Scale ${ }^{18}$ and classified as present using a modification of a standard diagnostic system ${ }^{19}$ in which we required a total score of $\geq 7$ and acknowledgment of any degree of depressed mood; medication use at 3 months after stroke (ie, medications administered to reduce the risk of stroke recurrence, including warfarin and aspirin; medications for the treatment of hypertension, diabetes mellitus, and cardiac disease; and a pooled grouping of other medications); recurrent stroke during follow-up; and other intercurrent illness during follow-up (ie, the occurrence or exacerbation of any medical or neurological disorder resulting in patient hospitalization, excluding recurrent stroke). We then performed a logistic regression analysis to determine whether any of the variables found to be related in the univariate analyses $(P<.10)$ would be independently related to exclusion from this study. Subjects 
excluded because of a diagnosis of Alzheimer's disease with stroke were not relevant for these analyses.

Because we administered multiple neuropsychological measures within most cognitive domains, we transformed the raw test scores for all subjects into $z$ scores based on the performance of the control group during their baseline assessment and then averaged those $z$ scores within each domain. When different numbers of verbal and nonverbal tasks were administered within a single cognitive domain, scores within the verbal and nonverbal subdomains were first averaged separately before the calculation of the domain-specific summary score to ensure that neither verbal nor nonverbal performance would be overrepresented. The domain scores were then averaged to produce a summary score representing generalized cognitive function. To investigate the duration of cognitive recovery, we operationally defined improvement within any annual interval as an increase in this summary score $>2$ SDs above the mean first annual control group change (specifically, an increase $>0.53$ ). Following the demonstration of improvement from the baseline examination to the first annual examination, a further significant increase in the neuropsychology summary score relative to first annual examination performance was required for additional improvement to be considered to have occurred. Stroke-related improvement was considered to have ended when a patient's annual change failed to exceed the specified cutoff.

To investigate the clinical correlates of long-term improvement, we performed $x^{2}$ analyses to compare the pooled group of all patients who exhibited improvement with those who did not exhibit improvement with regard to all of the clinical variables listed above. It should be noted that the reference group of patients who did not exhibit improvement was likely to have contained both patients with 
baseline stroke-related cognitive impairment who did not improve as well as patients who were free of such impairment and thus had no opportunity to improve. We then performed a logistic regression analysis to determine whether any of the variables found to be related in the univariate analyses would be independently related to improvement. Finally, we estimated the probabilities of long-term improvement for every combination of variables contained in the final logistic model using methods described elsewhere. ${ }^{20}$

\section{RESULTS}

\section{Potential Selection Biases}

Univariate analyses determined that patients who were excluded from this study had more frequently experienced a major hemispheral stroke syndrome, were more often diagnosed with dementia at baseline, and were less frequently taking medications to prevent stroke recurrence and treat hypertension than those who were included. A logistic regression analysis determined that dementia and the nonuse of medications indicated for the prevention of stroke recurrence and the treatment of hypertension were significant independent correlates of exclusion from this study, while a major hemispheral stroke syndrome was not related.

\section{Frequency of Long-term Improvement in Cognitive}

\section{Function}

Of the 151 patients who were examined at baseline, 136 patients were reevaluated 1 year after stroke, 13 patients received their first reevaluation 2 years after stroke, and 2 patients received their first reevaluation 3 years after stroke. Nineteen of the 151 stroke patients exhibited long-term improvement in cognitive function, with 17 of the 
19 patients exceeding the cutoff for improvement at the first annual examination and 2 patients who had missed that examination exceeding the cutoff for improvement when they were assessed at the second annual examination. Fourteen of the 19 patients were reevaluated at subsequent annual intervals, but none of them exhibited further improvement. Patients who improved were significantly more impaired in generalized cognitive function at baseline than patients who did not improve $(-1.77 \pm 1.08$ versus $-0.59 \pm 0.82, P<.001)$ and exhibited significantly greater change in the neuropsychology summary score between the two intervals at which improvement was demonstrated than patients who failed to improve exhibited between the first two intervals at which evaluations were completed $(0.78 \pm 0.24$ versus $-0.04 \pm 0.39, P<.001)$. Although it was not the primary focus of this study, it is worthy of note that patients who exhibited improvement in generalized cognitive function also exhibited greater increases in all domain-specific summary scores than patients who did not improve, with statistically significant improvement noted in memory $(0.25 \pm 0.33$ versus $0.01 \pm 0.51$, $P=.044)$, orientation $(2.63 \pm 2.17$ versus $-0.40 \pm 1.78, \quad P<.001)$, visuospatial function $(0.64 \pm 0.79$ versus $-0.05 \pm 0.69, P<.001)$, and attention $(0.86 \pm 1.19$ versus $0.06 \pm 0.74, P<.001)$ but not language $(0.10 \pm 0.65$ versus $0.05 \pm 0.52, P=.735)$ or abstract reasoning $(0.14 \pm 0.60$ versus $-0.02 \pm 0.63, P=.316)$.

\section{Clinical Correlates of Long-term Improvement in Cognitive Function}

Demographic characteristics, medical history, and neurological history of the stroke sample stratified by improvement status are shown in Table 1. Stroke characteristics at presentation, medication use, recurrent stroke, and other intercurrent illness stratified by 
improvement status are shown in Table 2. Univariate analyses determined that patients who exhibited long-term improvement had more frequently experienced left hemisphere infarction relative to brain stem/cerebellar infarction, a major hemispheral stroke syndrome, and neglect and were more often diagnosed with dementia at baseline than patients who did not improve, while they were less frequently diabetic. Aphasia was not significantly related to improvement.

Logistic regression analysis determined that long-term improvement was significantly related to left hemisphere infarction relative to brain stem/cerebellar infarction $(\mathrm{OR}, 5.57 ; 95 \% \mathrm{Cl}, 1.06$ to 29.25), while the presence of a major hemispheral stroke syndrome showed a trend toward significance (OR, 3.32; $95 \% \mathrm{Cl}, 0.84$ to 13.16). Diabetes mellitus was significantly associated with a failure to exhibit improvement (OR, $0.12 ; 95 \% \mathrm{Cl}, 0.02$ to 0.63 ). Based on the logistic model, the probability of long-term improvement in generalized cognitive function would be $54.0 \%$ for a patient with a left hemisphere infarct and a major hemispheral syndrome but only $11.9 \%$ if diabetes was also present. Probabilities of long-term improvement in cognitive function for every combination of variables contained in the final logistic model are shown in Table 3.

Although we adjusted for baseline cognitive impairment by including dementia status in our primary logistic regression analysis of the clinical predictors of improvement, we also repeated that analysis, adding the baseline neuropsychology summary score as a covariate. The final model was comparable, with left hemisphere infarction significantly associated with improvement relative to brain stem/cerebellar infarction (OR, 7.70;95\% Cl, 1.10 to 53.81) and diabetes mellitus associated with a failure to exhibit improvement (OR, $0.07 ; 95 \% \mathrm{Cl}, 0.01$ to 0.50 ). The baseline neuropsychology 
summary score was also significantly associated with improvement (OR, $0.12 ; 95 \% \mathrm{Cl}, 0.04$ to 0.34 ), with lower baseline scores tending to be associated with a greater increase in scores in subsequent evaluations, while the presence of a major hemispheral stroke syndrome was not related. Similar to the results of the preceding analysis, dementia status, aphasia, and neglect were not significant factors in the final model.

To ensure that the results of the primary logistic regression analysis were not an artifact of the dichotomization of the neuropsychology change scores, we also performed a multiple linear regression analysis. Given that we had found that improvement, when it occurred, was only evident between the first two completed examinations, we used change in the neuropsychology summary score from the baseline examination to the first completed annual examination as the continuous dependent variable. To facilitate interpretation of the results of this analysis, left hemisphere infarct location was compared with a pooled grouping of right hemisphere and brain stem/cerebellar infarct locations. Univariate analyses determined that change in test performance was related to left hemisphere infarction, a major hemispheral syndrome, and diabetes mellitus but not dementia or neglect. Consistent with the results of the logistic regression analysis, multiple linear regression analysis determined that change in test performance was independently related to left hemisphere infarction $(\beta=0.14, P=.090)$, a major hemispheral syndrome $(\beta=0.20, P=.017)$, and diabetes mellitus $(\beta=-0.21, P=.010)$.

\section{DISCUSSION}


Our results suggest that long-term improvement in generalized cognitive function can occur after stroke. We recognized long-term improvement in 19 of 151 patients (12.6\%), but it is unlikely that all of the 151 patients had cognitive impairment at baseline. Given that we have previously identified generalized cognitive impairment at 3 months after stroke in $35.2 \%$ of the larger cohort of patients from which the present sample was drawn, ${ }^{1}$ we can use that percentage to estimate that 53 of the 151 patients had cognitive impairment at baseline and that 19 of those 53 impaired patients, or $35.9 \%$, exhibited long-term improvement. Improvement was evident at the first annual examination in most cases, with stability of course usually demonstrated at the second annual examination.

Clinical correlates of improvement in cognitive function in our study included left hemisphere infarction and a major hemispheral stroke syndrome, while diabetes mellitus was associated with a failure to demonstrate improvement. Exclusion from our study was not independently related to those variables, suggesting that our estimates of the magnitude of the association between those variables and improvement were unlikely to have been significantly affected by selection bias. Exclusion from our study sample was associated with a baseline diagnosis of dementia, however, suggesting that our findings may not be generalizable to severely impaired patients. To the extent that the differential exclusion of patients with dementia may have reduced the proportion of the sample with cognitive impairment, and thus the potential for longterm improvement, our estimates of the frequency of improvement could be considered to be conservative. Exclusion was also related to the nonuse of medications indicated for the prevention of stroke recurrence and treatment of hypertension. Although it would not be appropriate to draw conclusions regarding the role of those 
medications in cognitive recovery because of the differential exclusion of untreated patients, we would hypothesize that the use of those medications would be associated with an increased probability of improvement to the extent that they might reduce the risk of recurrent brain infarction and subsequent cognitive decline.

Previous studies that have examined samples of stroke patients in long-term follow-up with multiple measures of cognitive function have not drawn explicit conclusions regarding the clinical correlates of improvement. Kotila et $\mathrm{al}^{21}$ evaluated 154 stroke patients with a comprehensive battery of neuropsychological tests and reported that the greatest improvement in cognitive function occurred from onset to 3 months after stroke, although they also recognized improvement on most measures throughout the first year after stroke. The frequencies of patients exhibiting resolution of deficits within specific cognitive domains from 3 months to 1 year after stroke ranged from $24 \%$ for general intelligence and memory to $3 \%$ for generalized language function. In a study focusing on memory functions, Wade et $\mathrm{al}^{22}$ recognized significant improvement in the mean scores of 85 patients tested 3 and 6 months after stroke on tasks tapping immediate and delayed verbal and nonverbal memory but not on a measure of digit span.

Given that left hemisphere infarction, independent of aphasia, was a significant correlate of long-term improvement in generalized cognitive function, our findings support the concept of the left hemisphere as the "dominant" or "major" hemisphere. Studies of the clinical correlates of long-term improvement have focused on recovery from specific deficits, such as aphasia or neglect, rather than generalized cognitive impairment. To the extent that recovery from specific deficits after left hemisphere infarction may parallel generalized cognitive improvement, however, the results of those 
studies could provide information relevant to our own findings. Although we did not recognize significant improvement in the language domain in our pooled group of patients who exhibited improvement in generalized cognitive function, studies of small samples of patients with aphasia have found that long-term improvement in specific aspects of language function can be recognized after left hemisphere infarction. ${ }^{23} 24252627282930 \quad 31$ Regarding nonverbal abilities, Sunderland et $\mathrm{al}^{32}$ reported that patients with left hemisphere infarction exhibited greater improvement than patients with right hemisphere infarction on the WAIS-R Block Design subtest from 1 to 6 months after stroke despite comparable baseline performance, a finding that was unrelated to the potentially confounding effects of aphasia in the left hemisphere infarct group or neglect in the right hemisphere infarct group. Given that we observed a trend toward significance for the association between a major hemispheral stroke syndrome and improvement, however, it should also be noted that patients with infarcts involving either cerebral hemisphere may exhibit long-term improvement in generalized cognitive function in a setting of more severe stroke.

We also recognized an association between diabetes mellitus and a failure to exhibit long-term improvement in cognitive function after stroke. We have previously reported that diabetes mellitus was one of many significant determinants of dementia at 3 months after stroke ${ }^{17}$ and that it was associated with cognitive dysfunction in subjects who were clinically free of stroke. ${ }^{33}$ Diabetes may have been related to a failure to exhibit long-term improvement in the present study by serving as the basis for clinically silent infarction. Diabetes has been reported to be associated with microangiopathy, which may lead to lacunar infarction, and in extreme cases 
"subcortical arteriosclerotic encephalopathy." 34 In the Framingham cohort, glucose intolerance was the only significant correlate of imaged but clinically silent lesions in patients with first stroke. ${ }^{35}$ Diabetes may also have transient effects on cognitive function, as well as on the ability to recover from stroke-related cognitive deficits, through its influence on CBF. Diabetes may produce disorders of autoregulation and reactivity, ${ }^{36}$ and the increased blood viscosity of diabetics $^{37}$ may contribute to reduced CBF. ${ }^{38}$ Changes in cerebral metabolism may parallel recovery from aphasia ${ }^{39} 40$ and neglect ${ }^{39} 41$ and may be evident in both cerebral hemispheres during recovery of cognitive functions that are thought to be represented in a single hemisphere. ${ }^{41}{ }^{42} \mathrm{It}$ is possible that disorders of CBF in diabetics interfere with those metabolic changes and thus compromise the recovery process.

Our study could be subject to certain criticisms. First, we included subjects in our baseline sample who may not have had cognitive deficits resulting from stroke and thus would not have been able to exhibit cognitive recovery. Traditional methods for the identification of subjects with cognitive impairment could fail to identify patients with mild new deficits who were premorbidly "high functioning" or cause the inclusion of subjects without stroke-related deficits who were premorbidly "low functioning" because of factors such as poor education. It is worthy of note that 11 of the 19 patients who exhibited long-term improvement (57.9\%) had baseline neuropsychology summary scores that did not fall more than 2 SDs below the mean baseline score of the control group, a common criterion for cognitive impairment. Thus, we decided to prospectively study an unselected sample of patients, a more conservative approach that would be expected to yield a smaller estimate of effect size than a study in which only patients with identified cognitive 
impairment were examined. Second, we performed follow-up examinations annually, which may have resulted in a less precise estimate of the duration of improvement than might have been derived if we had examined patients more frequently. Although the length of time between examinations should be short enough to allow some precision in the estimation of the duration of recovery, follow-up examinations should not be so frequent that improvement cannot be expected, learning effects might become a significant confounder, or subjects might become noncompliant. Third, we did not perform serial structural brain imaging, which would have enabled us to better understand the effects of recurrent infarction on the process of recovery. Similarly, as suggested by studies cited above, ${ }^{39} 404142$ serial functional imaging could have provided useful information relevant to metabolic changes that may occur in the brain during the process of recovery. Fourth, we did not investigate the role of glycemic control in our finding of an association between diabetes mellitus and a failure to exhibit cognitive improvement. Given that prior studies have reported a relationship between glucose level and cognitive function, with poorest performance associated with hypoglycemic and hyperglycemic states, ${ }^{43} 4445$ the results of future studies of the role of glycemic control in recovery of cognitive function could have implications for the management of diabetic patients after stroke.

Certain additional methodological issues are relevant to the design of future studies of the recovery of cognitive function after stroke. First, studies should examine a stroke-free reference group to define the expected amount of variation in test scores that would be unrelated to stroke. Second, the timing of the baseline examination should be planned carefully. If the baseline examination is performed soon after stroke, it is likely that cognitive deficits, and 
thus the potential for recovery, would be maximal. Third, the duration of prospective follow-up should be long enough for all subjects to demonstrate stability of course or complete recovery.

Although our results require external validation in a separate sample of stroke patients, they suggest that long-term improvement in generalized cognitive function can occur after stroke, particularly in patients who have experienced left hemisphere infarctions or more severe hemispheral stroke syndromes. Pharmacological interventions, or techniques such as cognitive remediation, might be incorporated into the long-term clinical care of stroke patients to maximize their ability to exhibit improvement in cognitive function. Diabetes mellitus, which may serve as the basis for recurrent infarction or disorders of CBF, can compromise the ability to exhibit long-term improvement in cognitive function after stroke, suggesting that management of that vascular risk factor should be performed with care and consistency.

\section{SELECTED ABBREVIATIONS AND ACRONYMS}

\begin{tabular}{|l|l|l|}
\hline CBF & $=$ & cerebral blood flow \\
\hline $\mathrm{Cl}$ & $=$ & confidence interval \\
\hline OR & $=$ & odds ratio \\
\hline WAIS-R & $=$ & Wechsler Adult Intelligence Scale-Revised \\
\hline
\end{tabular}

Table 1. Demographic Characteristics, Medical History, and Neurological History by Improvement Status (Table view)

\begin{tabular}{|l|l|l|l|}
\hline & \multicolumn{2}{|l|}{ Frequency (Within-Group Percentage) } & \\
\hline Variable & Improvement $(\mathrm{n}=19)$ & No Improvement $(\mathrm{n}=132)$ & $P^{\star}$ \\
\hline Age,$<70 \mathrm{y}$ & $8(42.1)$ & $73(55.3)$ & .281 \\
\hline Education, $>12 \mathrm{y}$ & $4(21.1)$ & $34(25.8)$ & .659 \\
\hline
\end{tabular}




\begin{tabular}{|l|l|l|l|}
\hline & \multicolumn{2}{|l|}{ Frequency (Within-Group Percentage) } & \\
\hline Variable & Improvement $(\mathrm{n}=19)$ & No Improvement $(\mathrm{n}=132)$ & $P^{\star}$ \\
\hline Race, nonwhite & $14(73.7)$ & $82(62.1)$ & .327 \\
\hline Sex, female & $12(63.2)$ & $65(49.2)$ & .257 \\
\hline Hypertension & $16(84.2)$ & $98(74.2)$ & .345 \\
\hline Diabetes mellitus & $2(10.5)$ & $48(36.4)$ & .025 \\
\hline Cardiac disease & $10(55.6)$ & $65(49.2)$ & .615 \\
\hline Hypercholesterolemia & $4(21.1)$ & $25(19.1)$ & .839 \\
\hline Consistent cigarette use & $11(57.9)$ & $77(58.8)$ & .942 \\
\hline Consistent alcohol use & $6(31.6)$ & $62(47.3)$ & .198 \\
\hline Prior stroke & $4(21.1)$ & $28(21.2)$ & .987 \\
\hline Prior transient ischemic attack & $3(16.7)$ & $27(20.8)$ & .685 \\
\hline
\end{tabular}

Due to missing data, within-group percentages are based on an incomplete sample of subjects for cardiac disease $(n=150)$, hypercholesterolemia $(n=150)$, consistent cigarette use $(n=150)$, consistent alcohol use $(n=150)$, and prior transient ischemic attack $(n=148)$.

${ }^{*} x^{2}$ analyses.

Table 2. Presenting Stroke Characteristics, Medication Use, Recurrent Stroke, and Other Intercurrent Illness by Improvement Status (Table view)

\begin{tabular}{|l|l|l|l|}
\hline & \multicolumn{2}{|l|}{ Frequency (Within-Group Percentage) } & \\
\hline Variable & $\begin{array}{l}\text { Improvement } \\
(n=19)\end{array}$ & $\begin{array}{l}\text { No Improvement } \\
(n=132)\end{array}$ & $P^{\star}$ \\
\hline Stroke location & & & \\
\hline Left hemisphere & $11(57.9)$ & $42(31.8)$ & .050 \\
\hline Right hemisphere & $6(31.6)$ & $47(35.6)$ & \\
\hline Brain stem/cerebellum & $2(10.5)$ & $43(32.6)$ & \\
\hline Major syndrome & $5(26.3)$ & $16(12.1)$ & .095 \\
\hline Aphasia & $3(15.8)$ & $11(8.3)$ & .295 \\
\hline Neglect & $2(10.5)$ & $2(1.5)$ & .022 \\
\hline Dementia & $5(26.3)$ & $16(12.1)$ & .095 \\
\hline Depression & $3(15.8)$ & $26(19.7)$ & .686 \\
\hline Medication use & & & .942 \\
\hline Warfarin/aspirin & $16(84.2)$ & $112(84.8)$ & .881 \\
\hline Antihypertensives & $12(63.2)$ & $81(61.4)$ & .130 \\
\hline Insulin/oral hypoglycemics & $2(10.5)$ & $35(26.5)$ & .245 \\
\hline Cardiac medications & $10(52.6)$ & $51(38.6)$ & \\
\hline & & & \\
\hline
\end{tabular}




\begin{tabular}{|l|l|l|l|}
\hline & Frequency (Within-Group Percentage) & \\
\hline Variable & $\begin{array}{l}\text { Improvement } \\
(\mathrm{n}=19)\end{array}$ & $\begin{array}{l}\text { No Improvement } \\
(\mathrm{n}=132)\end{array}$ & $P^{*}$ \\
\hline Other medications & $4(21.1)$ & $16(12.1)$ & .283 \\
\hline Recurrent stroke during follow-up & $0(0.0)$ & $6(4.5)$ & .343 \\
\hline $\begin{array}{l}\text { Other intercurrent illness during } \\
\text { follow-up }\end{array}$ & $3(15.8)$ & $25(18.9)$ & .741 \\
\hline
\end{tabular}

${ }^{*} x^{2}$ analyses.

Table 3. Probability of Long-term Improvement by Variables Contained in the Final Logistic Model (Table view)

\begin{tabular}{|l|l|}
\hline Variables & Probability of Improvement, \% \\
\hline LHI+MHS & 54.0 \\
\hline LHI & 26.1 \\
\hline MHS & 17.4 \\
\hline LHI+MHS+DM & 11.9 \\
\hline None & 6.0 \\
\hline LHI+DM & 3.9 \\
\hline MHS+DM & 2.4 \\
\hline DM & 0.7 \\
\hline
\end{tabular}

LHI indicates left hemisphere infarction; MHS, major hemispheral syndrome; and DM, diabetes mellitus.

\section{ARTICLE INFORMATION}

Received April 29, 1996; revision received June 10, 1996; accepted July 11, 1996.

\section{Note}

Presented in part at the 48th annual meeting of the American Academy of Neurology, San Francisco, Calif, March 28, 1996.

\section{Correspondence}

Correspondence to Dr Desmond, Neurological Institute, $710 \mathrm{~W}$ 168th St, New York, NY 10032. 


\section{Affiliations}

the Departments of Neurology (D.W.D., J.T.M., M.S., Y.S.) and Psychiatry (M.S., Y.S.) and the Gertrude H. Sergievsky Center (M.S., Y.S.), Columbia University, College of Physicians and Surgeons, New York, NY.

\section{Acknowledgments}

This work was supported by grants R01-NS26179 and P01-AG07232 from the National Institutes of Health. J.P. Mohr, MD, provided comments on this manuscript. The authors would like to acknowledge the contributions of the late Thomas K. Tatemichi, MD, without whose efforts this work would not have been possible.

\section{REFERENCES}

1. Tatemichi TK, Desmond DW, Stern Y, Paik M, Sano M, Bagiella E. Cognitive impairment after stroke: frequency, patterns, and relationship to functional abilities. $J$ Neurol Neurosurg Psychiatry. 1994;57:202-207. Crossref. PubMed.

2. Tatemichi TK, Desmond DW, Mayeux R, Paik M, Stern Y, Sano M, Remien R, Williams JBW, Mohr JP, Hauser WA, Figueroa M. Dementia after stroke: baseline frequency, risks, and clinical features in a hospitalized cohort. Neurology. 1992;42:1185-1193. Crossref. PubMed.

3. Erkinjuntti T, Autio L, Wikström J. Dementia in medical wards. J Clin Epidemiol. 1988;41:123-126. Crossref. PubMed.

4. Kase CS, Wolf PA, Bachman DL, Linn RT, Cupples LA. Dementia and stroke: the Framingham study. In: Ginsberg MD, Dietrich WD, eds. Cerebrovascular Diseases, 16th Research (Princeton) Conference. New York, NY: Raven Press; 1989:193-198.

5. Rocca WA, Bonaiuto S, Lippi A, Luciani P, Turtù F, Cavarzeran F, Amaducci L. Prevalence of clinically diagnosed Alzheimer's disease and other dementing disorders: a door-to-door survey in Appignano, Macerata Province, Italy. Neurology. 1990;40:626631. Crossref. PubMed.

6. Ueda K, Kawano H, Hasuo Y, Fujishima M. Prevalence and etiology of dementia in a Japanese community. Stroke. 1992;23:798-803. Crossref. PubMed.

7. Desmond DW, Stern Y, Sano M, Tatemichi TK. Risk factors for clinically significant cognitive decline after stroke. Cerebrovasc Dis. 1994;4:234. Abstract.

8. Kotila M, Waltimo O, Niemi ML, Laaksonen R. Dementia after stroke. Eur Neurol. 1986;25:134-140. Crossref. PubMed.

9. Tatemichi TK, Foulkes MA, Mohr JP, Hewitt JR, Hier DB, Price TR, Wolf PA. Dementia in stroke survivors in the Stroke Data Bank cohort: prevalence, incidence, risk factors, 
and computed tomographic findings. Stroke. 1990;21:858-866. Crossref. PubMed.

10. Aronovich BD, Treves TA, Bornstein NM, Korczyn AD. Dementia after first stroke: 3year survival analysis. Cerebrovasc Dis. 1992;2:216. Abstract. Crossref.

11. Tatemichi TK, Paik M, Bagiella E, Desmond DW, Stern Y, Sano M, Hauser WA, Mayeux R. Risk of dementia after stroke in a hospitalized cohort: results of a longitudinal study. Neurology. 1994;44:1885-1891. Crossref. PubMed.

12. Kinsella G, Ford B. Acute recovery patterns in stroke patients: neuropsychological factors. Med J Aust. 1980;2:663-666. PubMed.

13. Enderby P, Wood VA, Wade DT, Hewer RL. Aphasia after stroke: a detailed study of recovery in the first 3 months. Int Rehabil Med. 1987;8:162-165. PubMed.

14. Wade DT, Wood VA, Hewer RL. Recovery of cognitive function soon after stroke: a study of visual neglect, attention span and verbal recall. J Neurol Neurosurg Psychiatry. 1988;51:10-13. Crossref. PubMed.

15. Stern Y, Andrews H, Pittman J, Sano M, Tatemichi T, Lantigua R, Mayeux R. Diagnosis of dementia in a heterogeneous population: development of a neuropsychological paradigm-based diagnosis of dementia and quantified correction for the effects of education. Arch Neurol. 1992;49:453-460. Crossref. PubMed.

16. Foulkes MA, Wolf PA, Price TR, Mohr JP, Hier DB. The Stroke Data Bank: design, methods, and baseline characteristics. Stroke. 1988;19:547-554. Crossref. PubMed.

17. Tatemichi TK, Desmond DW, Paik M, Figueroa M, Gropen TI, Stern Y, Sano M, Remien $\mathrm{R}$, Williams JBW, Mohr JP, Mayeux R. Clinical determinants of dementia related to stroke. Ann Neurol. 1993;33:568-575. Crossref. PubMed.

18. Williams JBW. A structured interview guide for the Hamilton Depression Rating Scale. Arch Gen Psychiatry. 1988;45:742-747. Crossref. PubMed.

19. Endicott J, Cohen J, Nee J, Fleiss J, Sarantakos S. Hamilton Depression Rating Scale: extracted from regular and change versions of the Schedule for Affective Disorders and Schizophrenia. Arch Gen Psychiatry. 1981;38:98-103. Crossref. PubMed.

20. Kelsey JL, Thompson WD, Evans ES. Methods in Observational Epidemiology. New York, NY: Oxford University Press; 1986:113-119.

21. Kotila M, Waltimo $O$, Niemi ML, Laaksonen R, Lempinen $M$. The profile of recovery from stroke and factors influencing outcome. Stroke. 1984;15:1039-1044. Crossref. PubMed.

22. Wade DT, Parker V, Hewer RL. Memory disturbance after stroke: frequency and associated losses. Int Rehabil Med. 1986;8:60-64. Crossref. PubMed.

23. Sarno MT, Levita E. Some observations on the nature of recovery in global aphasia after stroke. Brain Lang. 1981;13:1-12. Crossref. PubMed. 
24. Knopman DS, Selnes OA, Niccum N, Rubens AB, Yock D, Larson D. A longitudinal study of speech fluency in aphasia: CT correlates of recovery and persistent nonfluency. Neurology. 1983;33:1170-1178. Crossref. PubMed.

25. Selnes OA, Knopman DS, Niccum N, Rubens AB, Larson D. Computed tomographic scan correlates of auditory comprehension deficits in aphasia: a prospective recovery study. Ann Neurol. 1983;13:558-566. Crossref. PubMed.

26. Knopman DS, Selnes OA, Niccum N, Rubens AB. Recovery of naming in aphasia: relationship to fluency, comprehension and CT findings. Neurology. 1984;34:14611470. Crossref. PubMed.

27. Sarno MT, Buonaguro A, Levita E. Gender and recovery from aphasia after stroke. $J$ Nerv Ment Dis. 1985;173:605-609. Crossref. PubMed.

28. Naeser MA, Helm-Estabrooks N, Haas G, Auerbach S, Srinivasan M. Relationship between lesion extent in 'Wernicke's area' on computed tomographic scan and predicting recovery of comprehension in Wernicke's aphasia. Arch Neurol. 1987;44:7382. Crossref. PubMed.

29. Ferro JM, Crespo M. Young adult stroke: neuropsychological dysfunction and recovery. Stroke. 1988; 19:982-986. Crossref. PubMed.

30. Pashek GV, Holland AL. Evolution of aphasia in the first year post-onset. Cortex. 1988;24:411-423. Crossref. PubMed.

31. Naeser MA, Gaddie A, Palumbo CL, Stiassny-Eder D. Late recovery of auditory comprehension in global aphasia: improved recovery observed with subcortical temporal isthmus lesion vs Wernicke's cortical area lesion. Arch Neurol. 1990;47:425432. Crossref. PubMed.

32. Sunderland A, Tinson D, Bradley L. Differences in recovery from constructional apraxia after right and left hemisphere stroke? J Clin Exp Neuropsychol. 1994;16:916-920. Crossref. PubMed.

33. Desmond DW, Tatemichi TK, Paik M, Stern Y. Risk factors for cerebrovascular disease as correlates of cognitive function in a stroke-free cohort. Arch Neurol. 1993;50:162166. Crossref. PubMed.

34. Schneider R, Klesewetter $\mathrm{H}$. The significance of microcirculatory disturbances in the pathogenesis of vascular dementia. Pharmacopsychiatry. 1988;21:11-16. Crossref. PubMed.

35. Kase CS, Wolf PA, Chodosh EH, Zacker HB, Kelly-Hayes M, Kannel WB, D'Agostino RB, Scampini L. Prevalence of silent stroke in patients presenting with initial stroke: the Framingham study. Stroke. 1989;20:850-852. Crossref. PubMed.

36. Dandona P, James IM, Newbury PA, Woolard ML, Beckett AG. Cerebral blood flow in diabetes mellitus: evidence of abnormal cerebrovascular reactivity. $\mathrm{Br}$ Med $\mathrm{J}$. 
1978;2:325-326. Crossref. PubMed.

37. Barnes AJ, Locke P, Scudder PR, Dormandy TL, Dormandy JA, Slack J. Is hyperviscosity a treatable component of diabetic microcirculatory disease? Lancet. 1977;2:789-791. Crossref. PubMed.

38. Kee DB, Wood JH. Influence of blood rheology on cerebral circulation. In: Wood JH, ed. Cerebral Blood Flow: Physiologic and Clinical Aspects. New York, NY: McGraw-Hill Book Co; 1987:173-185.

39. Vallar G, Perani D, Cappa SF, Messa C, Lenzi GL, Fazio F. Recovery from aphasia and neglect after subcortical stroke: neuropsychological and cerebral perfusion study. $J$ Neurol Neurosurg Psychiatry. 1988;51:1269-1276. Crossref. PubMed.

40. Heiss WD, Kessler J, Karbe H, Fink GR, Pawlik G. Cerebral glucose metabolism as a predictor of recovery from aphasia in ischemic stroke. Arch Neurol. 1993;50:958-964. Crossref. PubMed.

41. Perani D, Vallar G, Paulesu E, Alberoni M, Fazio F. Left and right hemisphere contribution to recovery from neglect after right hemisphere damage: an $\left[{ }^{18} \mathrm{~F}\right] \mathrm{FDG}$ PET study of two cases. Neuropsychologia. 1993;31:115-125. Crossref. PubMed.

42. Knopman DS, Rubens AB, Selnes OA, Klassen AC, Meyer MW. Mechanisms of recovery from aphasia: evidence from serial xenon 133 cerebral blood flow studies. Ann Neurol. 1984;15:530-535. Crossref. PubMed.

43. Holmes CS. Neuropsychological profiles in men with insulin-dependent diabetes. $J$ Consult Clin Psychol. 1986;54:386-389. Crossref. PubMed.

44. Pramming S, Thorsteinsson B, Theilgaard A, Pinner EM, Binder C. Cognitive function during hypoglycemia in type I diabetes mellitus. Br Med J. 1986;292:647-650. Crossref. PubMed.

45. Holmes CS, Hayford JT, Gonzalez JL, Weydert JA. A survey of cognitive functioning at different glucose levels in diabetic persons. Diabetes Care. 1983;6:180-185. Crossref. PubMed. 


\section{Sections}

1. Abstract

2. Subjects and Methods

1. Subjects

2. Test Instruments

3. Additional Procedures

4. Statistical Analyses

3. Results

1. Potential Selection Biases

2. Frequency of Long-term Improvement in Cognitive Function

3. Clinical Correlates of Long-term Improvement in Cognitive Function

4. Discussion

5. Selected Abbreviations and Acronyms

6. Article Information

1. Note

2. Correspondence

3. Affiliations

4. Acknowledgments

7. References 


\begin{tabular}{|l|l|l|}
\hline $\mathrm{CBF}$ & $=$ & cerebral blood flow \\
\hline $\mathrm{Cl}$ & $=$ & confidence interval \\
\hline $\mathrm{OR}$ & $=$ & odds ratio \\
\hline WAIS-R & $=$ & Wechsler Adult Intelligence Scale-Revised \\
\hline
\end{tabular}


Table 1. Demographic Characteristics, Medical History, and Neurological History by Improvement Status

\begin{tabular}{|l|l|l|l|}
\hline & \multicolumn{2}{|l|}{ Frequency (Within-Group Percentage) } & \\
\hline Variable & Improvement $(\mathrm{n}=19)$ & No Improvement $(\mathrm{n}=132)$ & $P^{\star}$ \\
\hline Age, $<70 \mathrm{y}$ & $8(42.1)$ & $73(55.3)$ & .281 \\
\hline Education, $>12 \mathrm{y}$ & $4(21.1)$ & $34(25.8)$ & .659 \\
\hline Race, nonwhite & $14(73.7)$ & $82(62.1)$ & .327 \\
\hline Sex, female & $12(63.2)$ & $65(49.2)$ & .257 \\
\hline Hypertension & $16(84.2)$ & $98(74.2)$ & .345 \\
\hline Diabetes mellitus & $2(10.5)$ & $48(36.4)$ & .025 \\
\hline Cardiac disease & $10(55.6)$ & $65(49.2)$ & .615 \\
\hline Hypercholesterolemia & $4(21.1)$ & $25(19.1)$ & .839 \\
\hline Consistent cigarette use & $11(57.9)$ & $77(58.8)$ & .942 \\
\hline Consistent alcohol use & $6(31.6)$ & $62(47.3)$ & .198 \\
\hline Prior stroke & $4(21.1)$ & $28(21.2)$ & .987 \\
\hline Prior transient ischemic attack & $3(16.7)$ & $27(20.8)$ & .685 \\
\hline
\end{tabular}

Due to missing data, within-group percentages are based on an incomplete sample of subjects for cardiac disease $(n=150)$, hypercholesterolemia $(n=150)$, consistent cigarette use $(n=150)$, consistent alcohol use $(n=150)$, and prior transient ischemic attack $(n=148)$.

${ }^{*} \chi^{2}$ analyses. 
Table 2. Presenting Stroke Characteristics, Medication Use, Recurrent Stroke, and Other Intercurrent IIIness by Improvement Status

\begin{tabular}{|l|l|l|l|}
\hline & \multicolumn{2}{|l|}{ Frequency (Within-Group Percentage) } & \\
\hline Variable & $\begin{array}{l}\text { Improvement } \\
(\mathrm{n}=19)\end{array}$ & $\begin{array}{l}\text { No Improvement } \\
(\mathrm{n}=132)\end{array}$ & $P^{\star}$ \\
\hline Stroke location & & & \\
\hline Left hemisphere & $11(57.9)$ & $42(31.8)$ & .050 \\
\hline Right hemisphere & $6(31.6)$ & $47(35.6)$ & \\
\hline Brain stem/cerebellum & $2(10.5)$ & $43(32.6)$ & .095 \\
\hline Major syndrome & $5(26.3)$ & $16(12.1)$ & .295 \\
\hline Aphasia & $3(15.8)$ & $11(8.3)$ & .022 \\
\hline Neglect & $2(10.5)$ & $2(1.5)$ & .095 \\
\hline Dementia & $5(26.3)$ & $16(12.1)$ & .686 \\
\hline Depression & $3(15.8)$ & $26(19.7)$ & \\
\hline Medication use & & & .942 \\
\hline Warfarin/aspirin & $16(84.2)$ & $112(84.8)$ & .881 \\
\hline Antihypertensives & $12(63.2)$ & $81(61.4)$ & .130 \\
\hline Insulin/oral hypoglycemics & $2(10.5)$ & $35(26.5)$ & .245 \\
\hline Cardiac medications & $10(52.6)$ & $51(38.6)$ & .283 \\
\hline Other medications & $4(21.1)$ & $16(12.1)$ & .343 \\
\hline Recurrent stroke during follow-up & $0(0.0)$ & $6(4.5)$ & .741 \\
\hline $\begin{array}{l}\text { Other intercurrent illness during } \\
\text { follow-up }\end{array}$ & $3(15.8)$ & $25(18.9)$ & \\
\hline
\end{tabular}

\section{${ }^{*} x^{2}$ analyses.}


Table 3. Probability of Long-term Improvement by Variables Contained in the Final Logistic Model

\begin{tabular}{|l|l|}
\hline Variables & Probability of Improvement, \% \\
\hline LHI+MHS & 54.0 \\
\hline LHI & 26.1 \\
\hline MHS & 17.4 \\
\hline LHI+MHS+DM & 11.9 \\
\hline None & 6.0 \\
\hline LHI+DM & 3.9 \\
\hline MHS+DM & 2.4 \\
\hline DM & 0.7 \\
\hline
\end{tabular}

LHI indicates left hemisphere infarction; MHS, major hemispheral syndrome; and DM, diabetes mellitus. 